\title{
Standardization of sternocleidomastoid for botulinum toxin applications*
}

\author{
Bilge İpek Torun ${ }^{1}$, Simel Kendir², Aysun $\mathrm{Uz}^{2}$ \\ ${ }^{1}$ Department of Anatomy, Faculty of Medicine, Ylldrrm Beyazıt University, Ankara, Turkey \\ ${ }^{2}$ Department of Anatomy, Faculty of Medicine, Ankara University, Ankara, Turkey
}

\begin{abstract}
Objectives: Botulinum toxin is frequently applied to the sternocleidomastoid muscle (SCM) for torticollis treatment. During this application, bulb of the jugular vein located under SCM makes the interventions unsafe. Also, injecting the botulinum toxin into the infrahyoid muscles which lie under SCM may cause hoarseness and swallowing disorders. The aim of this study was to describe the most reliable and appropriate botulinum toxin injection sites to the SCM to avoid injury to neighboring neurovascular structures and adjacent muscles.

Methods: In ten male cadavers, SCM was evaluated in three equal segments (upper, middle and lower). Muscle width and thickness at the center of each segment were measured. In one male cadaver, colored latex was injected according to the results of the measurements.

Results: The respective mean width of upper, medial and lower segments were 33.15 (23-41) mm, 36.45 (28-45) mm and, 39.35 (15-50) mm, respectively. The mean thickness of upper, medial and lower segments were 5.29 (3.87-7.68) mm, 5.89 (3.56-8.32) $\mathrm{mm}$ and $3.60(0.69-7.75) \mathrm{mm}$, respectively. There was no significant difference between the right and left sides. The thickest part of the muscle was the middle part, and the lower part was the thinnest. When the colored latex injected cadaver was dissected, the center of the muscle was observed as colored, while the neighboring structures were avoided. The thickest and safest part of SCM for the botulinum toxin injections was the middle part.
\end{abstract}

Conclusion: Knowing the thickness of SCM will make the botulinum toxin applications to this muscle safer and easier.

Keywords: botulinum toxin; muscle thickness; sternocleidomastoid; swallowing disorder; torticollis

Anatomy 2017;11(3):128-132 @2017 Turkish Society of Anatomy and Clinical Anatomy (TSACA)

\section{Introduction}

Torticollis is the most common form of cervical dystonia presenting short sternocleidomastoid (SCM) with an abnormal head and neck posture. ${ }^{[1]}$ The head tilts towards the short SCM, and the jaw turns to the opposite side. Torticollis is a common disease in all age groups, from newborn to adult. ${ }^{[2]}$

Successful use of botulinum toxin in the treatment of cervical dystonia has significantly changed the prognosis of patients. In many studies up to now, botulinum toxin has superiority over other pharmacotherapies both in terms of efficacy and less side effects. ${ }^{[1]}$ Botulinum toxin injection into the SCM reduces involuntary head movement and pain causing local muscle weakness. ${ }^{[3]}$
When botulinum toxin is applied for torticollis, the inferior bulb of the jugular vein just below the SCM makes the interventions dangerous. ${ }^{[4]}$ Furthermore, chemodenervation of the SCM with botulinum toxin may cause dysphagia, effecting the infra- and suprahyoid muscles underlying the SCM. Retrospective studies of the dose and injection site have shown that dysphagia is associated with toxin injection to SCM. ${ }^{[5]}$ According to experts, it is very important for the physician to know the anatomy of the cervical region in order to be able to successfully identify the muscles to be injected. ${ }^{[1]}$

In this study, we aimed to describe the most reliable and appropriate botulinum toxin injection site of the

*This study was an oral presentation at the VIII International Symposium of Clinical and Applied Anatomy (ISCAA), September 1-3, 2016, Budapest. 
muscle which has no risk of injury to neighboring vascular structures and adjacent muscles.

\section{Materials and Methods}

This study was performed on formaldehyde fixed 11 adult cadavers from the cadaver collection of Department of Anatomy, Ankara University School of Medicine. The mean age of the cadavers was 55 (range: 24-87). There was no sign of previous surgery or cervical dystonia in the neck region. Ten of these cadavers were bilaterally dissected to expose the SCM. Muscle length, width and thickness of SCM were measured on the dissected cadavers. In one male cadaver, colored latex injection was applied instead of botulinum toxin to muscle segments determined according to the results obtained in this study, bilaterally.

The cadavers were put in supine position, skin and platysma was removed from the underlying facial structures to expose SCM. To measure the length of the SCM, the midpoints of the origin and insertion points were selected. For this, initially the anterior and posterior edges of the SCM were palpated where it inserted on the mastoid process. Midpoint of the insertion side behind the mastoid process (A) was detected. Then a line connecting this point to sternoclavicular joint (B) was drawn, and the distance between $\mathrm{A}-\mathrm{B}$ points was measured. This distance allowed us to determine the length of the muscle. Then the length of the muscle was divided into three equal parts and the width and the thickness of the center point of each muscle section was measured (Figure 1). We chose the midpoints of each segment to be sure that we measured the width and the thickness of the muscle segments through the same reference point.
The results were statistically evaluated by IBM SPSS (Statistical Package for the Social Sciences, version 20.0; IBM, Chicago, IL, USA) software. According to the results of the study, colored latex was applied on one cadaver, bilaterally. For this procedure, mastoid process (A) the insertion of the SCM and the sternoclavicular joint (B) the origin of the SCM were palpated and marked on the skin. A-B distance was measured. According to the distance, SCM was divided to three equal segments and the mid-points of each segment of the muscle were marked on the skin. Then at the same level, the width of the muscle was palpated and the center of the muscle was marked. Then colored latex was injected into the mid-point of the muscle. Later, the muscles were dissected and then it was observed whether they were colored.

All the measurements were done with a digital caliper sensitive to $0.01 \mathrm{~mm}$ and performed by the same observer in the same anatomical position. The results were statistically evaluated by Wilcoxon's signed rank test.

\section{Results}

The mean length of the SCM was measured as 188.65 $\mathrm{mm}$ (range: 160-220). There was no statistically significant difference between right and left sides. The respective mean widths of upper $1 / 3$, middle $1 / 3$ and lower $1 / 3$ of the muscle were measured as 33.15 (range: 23-41) $\mathrm{mm}, 36.45$ (range: $28-45$ ) $\mathrm{mm}$ and 39.35 (range: 15-50) $\mathrm{mm}$, and the thicknesses were 5.29 (range: 3.87-7.68) $\mathrm{mm}, 5.89$ (range: 3.56-8.32) $\mathrm{mm}$ and 3.60 (range: $0.69-7.75) \mathrm{mm}$ (Table 1). There was no statistically significant difference between right and left sides.

The results were evaluated statistically and it was found that the ideal site of botulinum toxin injection was

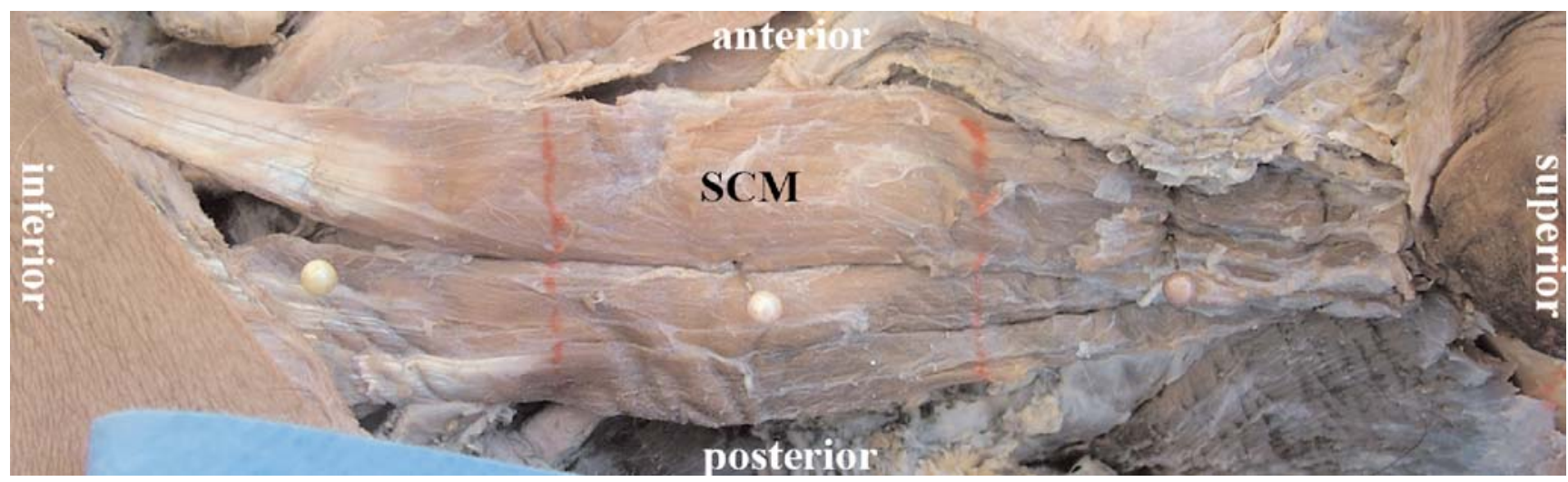

Figure 1. Measurement of width, thickness and length of the left SCM. SCM: sternocleidomastoid muscle. [Color figure can be viewed in the online issue, which is available at www.anatomy.org.tr] 
the middle $1 / 3$ of the muscle, being the thickest part of the muscle and relatively far from the vascular structures. Accordingly, red colored latex instead of botulinum toxin was injected into the center of SCM of one cadaver bilaterally. Than the muscle was dissected and it was observed that the muscle was colored, while the neighboring muscles and veins were not (Figure 2).

\section{Discussion}

Currently, botulinum toxin is frequently used for the treatment of some diseases such as strabismus, ${ }^{[6]}$ cervical dystonia, ${ }^{[3,7]}$ hyperfunctional larynx ${ }^{[8]}$ pain-headache, ${ }^{[9]}$ temporomandibular diseases, ${ }^{[10]}$ bruxism, ${ }^{[1]]}$ and for aesthetic purposes. ${ }^{[12]}$ During botulinum toxin application to SCM for cervical distonia treatment, complications such as dysphagia ${ }^{[4]}$ paralysis in neighboring muscles ${ }^{[13]}$ dry mouth, hoarseness and weakness in neck muscles ${ }^{[14]}$ may be encountered. There are also studies suggesting that spread of toxin to neighboring muscles depends on the amount of toxin given. ${ }^{[4]}$ On the other hand, studies report the spread of toxin to neighboring muscles even in low doses. Thus, applying botulinum toxin to the center of muscle was suggested. ${ }^{[13]}$ Because of the proximity of the SCM with the inferior bulb of jugular vein, there is also risk of injury to this vessel during botulinum toxin application. It is important to know the thickness of SCM so that the procedure can be performed safely.

Studies evaluating the thickness of SCM for botulinum toxin injections are limited in the literature. Hong et al. ${ }^{[15]}$ reported that the thickness of the SCM was less than 1.1 $\mathrm{cm}$ from the skin using ultrasound. Although this study does not specify the region where the thickness of the muscle was measured, the results are compatible with our measurements. Also, according to the same study, it was stated that the muscle thicknesses in the patients and the
Table 1

Mean, standard deviation (SD) and range of the SCM.

\begin{tabular}{llccc}
\hline & & Mean $(\mathbf{m m})$ & SD & Range $(\mathbf{m m})$ \\
\hline \multirow{2}{*}{ Width } & Upper & 33.15 & $23-41$ & 4.61 \\
& Middle & 36.45 & $28-45$ & 4.46 \\
& Lower & 39.35 & $15-50$ & 8.7 \\
\hline \multirow{2}{*}{ Thickness } & Upper & 5.29 & $3.87-7.68$ & 0.96 \\
& Middle & 5.89 & $3.56-8.32$ & 1.06 \\
& Lower & 3.60 & $0.69-7.75$ & 1.47 \\
\hline Length & & 188.65 & 15.52 & $160-220$ \\
\hline
\end{tabular}

normal group did not differ. Although a group of cervical distonia patients may develop muscle hypertrophy, it was suggested that muscle atrophy develops due to recurrent botulinum toxin injections.

In an ultrasonographic study performed by Arts et al., ${ }^{[16]}$ the thickness of SCM was reported to differ between males and females, but there was no significant difference between right and left sides. Muscle thickness was measured as $1.01 \mathrm{~cm}$ in males and $0.87 \mathrm{~cm}$ in females. In this study, muscle thickness was measured from the middle of the muscle and was found thicker than our measurements. The authors noted that the measurements may change in other populations because they selected samples from Western European populations. Likewise, since the samples in our study are from the Turkish population, we are of the opinion that the results may differ according to other populations.

Park et al. ${ }^{[17]}$ found that SCM and internal jugular vein were significantly far from each other in anatomical position when the head is rotated $30^{\circ}$ to the opposite side. According to the results of our study, the mid-third of SCM was both a thicker and reliable place for botulinum

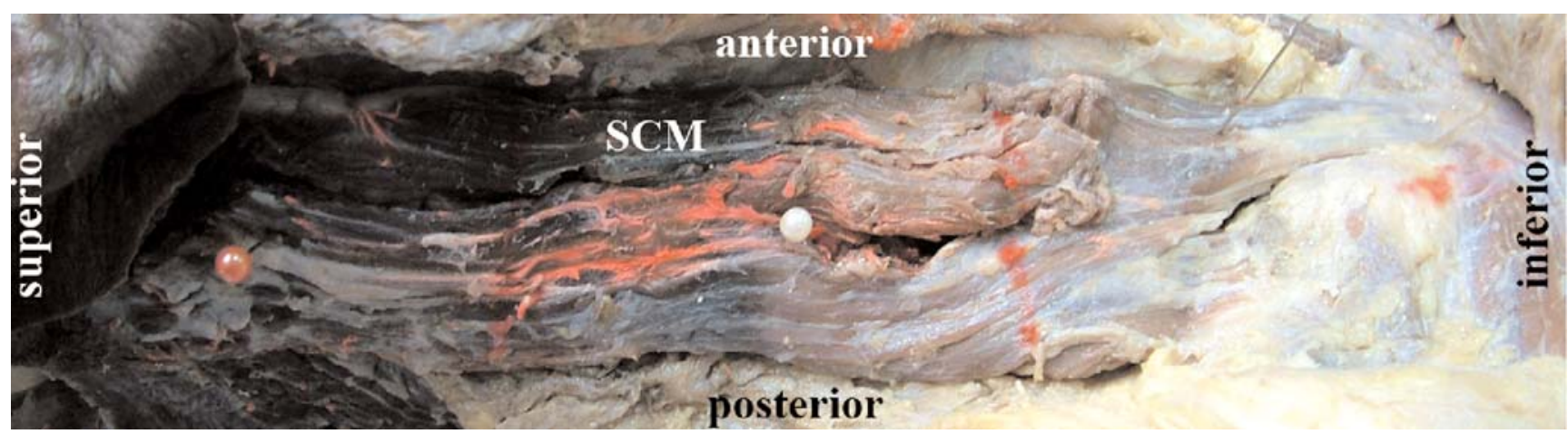

Figure 2. The right SCM colored with red latex. SCM: sternocleidomastoid muscle. [Color figure can be viewed in the online issue, which is available at www.anatomy.org.tr] 
toxin application, because it is far from the inferior bulb of the jugular vein. We suggest this is a more reliable method when combined with the head rotation described by Park et al. ${ }^{[17]}$

Botulinum toxin blocks acetylcholine release from nerve motor endings and causes the typical flaccid paralysis. Botulinum toxin types are di-chain polypeptides formed by two subunits: heavy chain $(\mathrm{H})$ and light chain (L). The $\mathrm{H}$ chain binds to perypheral cholinergic synapses with specific receptors leading to internalization of the $\mathrm{L}$ chain. The $\mathrm{L}$ chain targets SNARE proteins or synaptobrevin required for the release of acetylcholine into the synaptic cleft irreversibly. ${ }^{[18]}$ Animal experiments showed that the closer injection to the motor end point of the muscle's nerve causes the more effective botulinum toxin application. ${ }^{[19]}$ There are studies in the literature about the location of motor end plates on SCM. According to the study of Lee et al., ${ }^{[20]}$ the motor end plates on SCM mostly locate on upper-middle part of the muscle. Combining this knowledge with our measurements, upper and middle segments of SCM could be suggested as the most appropriate parts for botulinum toxin injections. In a study of Delnooz et al., ${ }^{[21]}$ the exact location of the motor end plates of SCM was revealed and they achieved equivalent results in full dose with a half dose of botulinum toxin. When the results obtained in such studies are used together with the results obtained in our study, we think that safer and more effective botulinum toxin applications can be made.

When applying botulinum toxin to SCM, the depth of the muscle also should be known. For this, the thickness of skin on SCM should be measured. Skin thickness varies depending on some factors such as age, gender and body mass index, but can be approximately measured squeezing the skin between two fingers.

The most important limitation of our study was that the measurements were made on formaldehyde-fixed cadavers. It should be kept in mind that there may be $4 \%$ loss of tissue when measuring muscle thickness on formaldehyde-fixed cadavers as described by Loukas et al. ${ }^{[2]}$ and Apaydin et al. ${ }^{[23]}$ Also, the measurements were made on cadavers without cervical distonia Although the thickness of the SCM may change in these patients, it is important to keep in mind that the knowledge of normal thickness of the muscle and the planning the interventions accordingly will be helpful in patients with cervical distonia. One more limitation was that the study was performed on only male cadavers. Studies on also female cadavers will be useful for both increasing the number of measurements and making statistical comparisons.

\section{Conclusion}

In this study, the length and thickness of SCM was measured in order to perform botulinum toxin applications safely. The mean length of SCM was found as 188.65 $\mathrm{mm}$, the thickest part of the muscle was shown as the middle third as $5.89 \mathrm{~mm}$, and the thinnest part was the lower third as $3.6 \mathrm{~mm}$. We suggest that the middle part of the muscle is the safest part for botulinum toxin applications, because it is the thickest part and has relatively far distance from the inferior bulb of the jugular vein. Since the lower third of the muscle is the closest part to the inferior bulb of jugular vein and since it is the thinnest part of the muscle, we recommend avoiding botulinum toxin applications to this area.

As conclusion, knowing the thickness of SCM throughout its course according to the measurements obtained in our study will make the botulinum toxin applications to this muscle safer and easier.

\section{References}

1. Hanagasi HA. Cervical dystonia and botulinum toxin treatment. Nöropsikiyatri Arşivi 2006;43:27-30.

2. Tomczak KK, Rosman NP. Torticollis. J Child Neurol 2013;28:365_78.

3. Bledsoe IO, Comella CL. Botulinum toxin treatment of cervical dystonia. Semin Neurol 2016;36:47-53.

4. Bhidayasiri R. Treatment of complex cervical dystonia with botulinum toxin: involvement of deep-cervical muscles may contribute to suboptimal responses. Parkinsonism Relat Disord 2011;17:S20-4.

5. Borodic GE, Joseph M, Fay L, Cozzolino D, Ferrante RJ. Botulinum A toxin for the treatment of spasmodic torticollis: dysphagia and regional toxin spread. Head Neck 1990;12:392-9.

6. Scott AB. The role of botulinum toxin type A in the management of strabismus. In: Scientific and therapeutic aspects of botulinum toxin. Brin MF, Hallett M, Jankovic J, editors. Philadelphia (PA): Lippincott Williams and Wilkins; 2002. p. 189-95.

7. Comella CL. Cervical dystonia: treatment with botulinum toxin serotype $\mathrm{A}$ as Botox or Dysport. In: Scientific and therapeutic aspects of botulinum toxin. Brin MF, Hallett M, Jankovic J, editors. Philadelphia (PA): Lippincott Williams and Wilkins; 2002. p. 359 364.

8. Blitzer A, Zalvan C, Gonzalez-Yanez O, Brin MF. Botulinum toxin type A injections for the management of the hyperfunctional larynx. In: Brin MF, Hallet M, Jankovic J, editors. Scientific and therapeutic aspects of botulinum toxin. Philadelphia (PA): Lippincott Williams and Wilkins; 2002. p.207-16.

9. Brin MF, Binder W, Blitzer A. Botulinum toxin type A BOTOX for pain and headache. In: Brin MF, Hallett M, Jankovic J, editors. Scientific and therapeutic aspects of botulinum toxin. Philadelphia (PA): Lippincott Williams and Wilkins; 2002. p. 233-50.

10. Schwartz MFB. Botulinum toxin A therapy for temporomandibular disorders. In: Brin MF, Hallett M, and Jankovic J, editors. Scientific and therapeutic aspects of botulinum toxin. Philadelphia (PA): Lippincott Williams and Wilkins; 2002. p. 259. 
11. Tintner RJJ. Botulinum toxin type A in the management of oromandibular dystonia and bruxism. In: Brin MF, Hallett M, and Jankovic J, Editors. Scientific and therapeutic aspects of botulinum toxin. Philadelphia (PA): Lippincott Williams and Wilkins; p. 343-50.

12. Stephan S, Wang TD. Botulinum toxin: clinical techniques, applications, and complications. Facial Plast Surg 2011;27:529-39.

13. Shaari CM, George E, Wu BL, Biller HF, Sanders I. Quantifying the spread of botulinum toxin through muscle fascia. Laryngoscope 1991;101:960-4.

14. Anderson TJ, Rivest J, Stell R, Steiger MJ, Cohen H, Thompson PD, Marsden CD. Botulinum toxin treatment of spasmodic torticollis. J R Soc Med 1992;85: 524-9.

15. Hong JS, Sathe GG, Niyonkuru C, Munin MC. Elimination of dysphagia using ultrasound guidance for botulinum toxin injections in cervical dystonia. Muscle Nerve 2012;46:535-9.

16. Arts IM, Pillen S, Schelhaas HJ, Overeem S, Zwarts MJ. Normal values for quantitative muscle ultrasonography in adults. Muscle Nerve 2010;41:32-41.

17. Park SY, Kim MJ, Kim MG, Lee SJ, Kim SH, Ok SY, Kim SI Changes in the relationship between the right internal jugular vein and an anatomical landmark after head rotation. Korean J Anesthesiol 2011;61:107-11.

18. Proverbio MR, Lamba M, Rossi A, Siani P. Early diagnosis and treatment in a child with foodborne botulism. Anaerobe 2016;39: 189-92.

19. Ye JF, Lee JH, An XC, Lin CH, Yue B, Han SH. Anatomic localization of motor entry points and accurate regions for botulinum toxin injection in the flexor digitorum superficialis. Surg Radiol Anat 2011;33:601-7.

20. Lee JH, Lee BN, Han SH, An XC, Chung RH. The effective zone of botulinum toxin A injections in the sternocleidomastoid muscle. Surg Radiol Anat 2011;33:185-90.

21. Delnooz CC, Veugen LC, Pasman JW, Lapatki BG, van Dijk JP, van de Warrenburg BP. The clinical utility of botulinum toxin injections targeted at the motor endplate zone in cervical dystonia. Eur J Neurol 2014;21:1486-98.

22. Loukas M, Louis RG Jr, Childs RS. Anatomical examination of the recurrent artery of Heubner. Clin Anat 2006;19:25-31.

23. Apaydin N, Uz A, Evirgen O, Loukas M, Tubbs RS, Elhan A. The phrenico-esophageal ligament: an anatomical study. Surg Radiol Anat 2008;30:29-36.

Correspondence to: Bilge Ipek Torun, MD Department of Anatomy, Faculty of Medicine, Yıldırım Beyazıt University, Ankara, Turkey

Phone: +90 5322468778

e-mail: bilgeipek@yahoo.com

Conflict of interest statement: No conflicts declared.

This is an open access article distributed under the terms of the Creative Commons Attribution-NonCommercial-NoDerivs 3.0 Unported (CC BY-NCND3.0) Licence (http://creativecommons.org/licenses/by-nc-nd/3.0/) which permits unrestricted noncommercial use, distribution, and reproduction in any medium, provided the original work is properly cited. Please cite this article as: Torun Bİ, Kendir S, Uz A. Standardization of sternocleidomastoid for botulinum toxin applications. Anatomy 2017;11(3):128-132. 